\title{
Assessment of Malnutrition in Chronic Liver Disease Patients with the Child Pugh Classification at a Large Tertiary Care Center in Karachi, Pakistan
}

\author{
Aamna Qazi ${ }^{1}$, Saqib Basar², Azka Qazi ${ }^{3}$, Lubna Shafi ${ }^{4}$, Rabia Qazi ${ }^{5}$
}

\author{
1 Resident Medical Officer, Medical Unit III Dr. Ruth K.M. Pfau Civil Hospital, Karachi Pakistan \\ 1 Concept, Drafting, Layout, Data collection, Corresponding author \\ 2 Dow University of Health Sciences, Karachi Pakistan \\ 2 Concept, Write-up, Drafting, Data collection, Layout \\ Post-Graduate Trainee, Medical Unit II, Dr. Ruth K.M. Pfau Civil Hospital, Karachi Pakistan \\ 3 Concept, Drafting, Literature review data collection \\ 4 Senior Registrar, Dow University of Health Sciences, Karachi Pakistan \\ 4 Concept, Drafting, Layout \\ 5 Infectious Disease Fellow, Hamad Medical Corporation, Pakistan \\ 5 Data entry, Statistical analysis
}

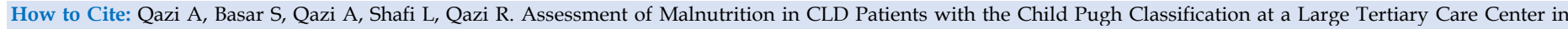
Karachi, Pakistan. APMC 2021;15(1):1-5. DOI: 10.29054/APMC/2021.1155

\section{ABSTRACT}

Background: Child Pugh classification is an easy-to-use method that allows Physicians to assess malnutrition in patients suffering from CLD. Objective: To determine the frequency of malnutrition at different stages of chronic liver disease in accordance with Child Pugh classification. Study Design: The type of study is a cross-sectional study. Settings: Medical Unit III Civil Hospital, Karachi Pakistan. Duration: Six months from 31 $1^{\text {st }}$ May 2016 to 30 $0^{\text {th }}$ November 2016. Methodology: All the patients between the age 30 to 60 years who are known cases of CLD secondary to hepatitis B, C or both, with active signs of CLD were included. All the patients having debilitating co-morbidities likes malignancy, TB, psychiatric, etc. were excluded. Anthropometric evaluation and lab investigation at the time of admission were performed for all the patients. Results: The average age was $48.12 \pm 8.521$ years and duration of disease was $5.48 \pm 3.792$ months. There were $61.54 \%$ male and $38.46 \%$ females. Hepatitis-B was observed in $19.91 \%(n=44)$ cases, Hepatitis- $\mathrm{C}$ was $62.44 \%(n=62.44)$ and both hepatitis $\mathrm{B}$ and $\mathrm{C}$ was observed in $17.65 \%(\mathrm{n}=39)$ cases. According to Child Pugh score, $9.5 \%$ cases were in class A, $32.58 \%$ were in class B and $57.92 \%$ were in class C. Frequency of malnutrition in chronic liver disease patients was $62.44 \%(138 / 221)$. Rate of malnutrition was significantly high in class $B$ and $C(p=0.002)$. Rate of malnutrition was also observed to be significantly high in those cases who were positive for both hepatitis like B and $C(p=0.001)$. Effect of duration of cirrhosis was also not statistically significant with malnutrition. Conclusion: Malnutrition was significantly common among chronic liver disease patients regardless of viral etiology. Child Pugh B \& C patients were found to have more significant malnourished states.

Keywords: Chronic liver diseases, Child Pugh classification, Hepatitis, Malnutrition.

\section{INTRODUCTION}

Chronic liver disease (CLD) is one of the common causes of hospital admission and long hospital stays in Pakistan. The two etiologies mostly responsible for CLD in Pakistan are the viral illnesses Hepatitis B and C. In Pakistan there is a high burden of chronic liver disease as well. ${ }^{2}$ In Pakistan the prevalence of hepatitis B among healthy adults was $2.4 \%$ and for hepatitis $C$ was $3.0 \% .^{2}$ It is within the first 12 mortality causes in United States ${ }^{1}$ resulting in about 35000 deaths per year. Its estimated prevalence is $0.15 \%$ or 1 in 679 of the USA population. ${ }^{1}$ Greater than fifty percent of patients with chronic liver disease suffer from malnutrition. ${ }^{1}$ Multifactorial etiology plays a role and the malnutrition can be secondary to lowered intake of nutrients due to dietary restrictions and lack of appetite. ${ }^{3}$ In patients suffering from malnourishment eighty percent of their body's protein sources are used up, this especially being the case for patients suffering from decompensated liver cirrhosis. A damaged liver demands extra protein supply to maintain its dwindling physiology. This compounds the need for protein by the body. Malnourished patients have higher rate of complications like ascites, encephalopathy, spontaneous bacterial peritonitis, hepatorenal syndrome and a poor quality of life. ${ }^{4}$ It is an independent predictor of mortality and leads to more frequent hospital admissions. ${ }^{5}$ Malnourished patients have higher pace of clinical complications like ascites, encephalopathy, bacterial peritonitis, hepatorenal disorder and a low quality of life. It is an indicator of mortality and prompts more successive clinical research. ${ }^{4,5}$ Also, patients who underwent liver transplantation secondary to liver disease, nutritional status implies prognosis. According to Shaheen et al, $82.6 \%$ of cirrhotic patients suffer 
malnutrition. ${ }^{5}$ It is well known that hepatic encephalopathy has a strong association with CLD. ${ }^{4}$ Having known that patients suffering from CLD require a higher quantity of protein intake, previous practices used to limit patients' intakes. There appears to be a need of a paradigm shift towards the "educational inertia" surrounding protein restriction in cirrhosis.

Chronic liver disease can be classified based on Child Pugh classification. According to Ndhara et al, ${ }^{6}$ among 38 patients, there were 4 patients in Child Pugh A of which $1(25 \%)$ is malnourished, 15 in Child Pugh B of which 07(46.66\%) were malnourished and 19 patients in Child Pugh C of which $17(89.47 \%)$ were malnourished. The rationale of our study is to determine the frequency of malnutrition in and at different stages of chronic liver disease in accordance with Child Pugh classification at a large tertiary care center in Karachi, Pakistan. Till the time of this writing no specific guidelines exist regarding the management of malnutrition, ideal protein intake, or the upper limits of recommended intake in patients with CLD.

\section{METHODOLOGY}

Study Design: Prospective cross-sectional study.

Settings: Medical Unit-III Civil Hospital, Karachi Pakistan.

Duration: A period of six months from 31 ${ }^{\text {st }}$ May 2016 to 30th November 2016.

Sample Technique: The sampling technique utilized was non-probability, consecutive sampling technique.

Sample Size: Sample size was $\mathrm{n}=221$

Inclusion Criteria: The inclusion criteria were all the patients between the ages of 30 to 60 years who are known cases of chronic liver disease secondary to hepatitis B, C or both, with active signs of chronic liver disease.

Exclusion Criteria: The exclusion criteria were all the patients having debilitating co-morbidities likes malignancy, TB, psychiatric, mal absorption illnesses, patients who have inconsistent housing situations and patients who previously had received parenteral nutrition for more than three days for any cause were excluded.

Data Collection Procedure: All the patients duly signed a full informed consent to participate in the study, and our study was approved by the hospital ethics committee. Anthropometric evaluation and lab investigation at the time of admission were performed for all the patients. Triceps skin fold thickness ( $\mathrm{mm}$ ) and mid upper arm circumference were also measured. All measurements were performed on the non-dominant arm by the same person.

Data Analysis: Data was analyzed through SPSS version 21. Mean \pm and standard deviation was calculated for all continuous variables. Frequency and percentages were calculated for all qualitative variables. To compare malnutrition between different stages of Chronic liver disease Chi square test was applied. Effect modifiers like age, gender and duration of symptoms was dealt through stratification. Post stratification Chi square test was applied. $\mathrm{P}$ value $<0.05$ was taken as significant.

\section{RESULTS}

Two twenty-one patients diagnosed as chronic liver disease secondary to hepatitis B, C or both, with signs of chronic liver disease were enrolled in this study. Most of the patients were above 40 years and the average age was $48.12 \pm 8.521$ years and duration of disease was $5.48 \pm 3.792$ months respectively. The average triceps skin fold thickness, mid upper arm circumference, mid arm muscle circumference is also shown in table 1.

Table 1: Descriptive statistics of study patients.

\begin{tabular}{|c|c|c|c|c|c|c|}
\hline Variables & Mean & SD & $\begin{array}{c}\text { 95\% } \\
\text { Confidence } \\
\text { Interval for } \\
\text { Mean }\end{array}$ & Median & IQR \\
\cline { 3 - 6 } & & $\begin{array}{c}\text { Lower } \\
\text { Bound }\end{array}$ & $\begin{array}{c}\text { Upper } \\
\text { Bound }\end{array}$ & & \\
\hline Age (Years) & 48.12 & 8.521 & 46.99 & 49.25 & 50 & 15 \\
\hline $\begin{array}{c}\text { Duration of } \\
\text { Disease (months) }\end{array}$ & 5.48 & 3.792 & 4.97 & 5.98 & 5 & 5 \\
\hline $\begin{array}{c}\text { Triceps skin fold } \\
\text { thickness(cm) }\end{array}$ & 14.80 & 2.08 & 14.52 & 15.07 & 15 & 3.8 \\
\hline $\begin{array}{c}\text { Mid upper arm } \\
\text { circumference(cm) }\end{array}$ & 26.65 & 2.96 & 26.26 & 27.05 & 26 & 3.0 \\
\hline $\begin{array}{c}\text { Mid arm muscle } \\
\text { circumference(cm) }\end{array}$ & 22.02 & 3.26 & 21.58 & 22.45 & 21.45 & 3.2 \\
\hline SD = Standard Deviation & & & & & \\
\hline
\end{tabular}

There were $61.54 \%$ male and $38.46 \%$ females. Regarding hepatitis status, Hepatitis-B was observed in 19.91\% $(n=44)$ cases, Hepatitis- $C$ was $62.44 \%(n=62.44)$ and both hepatitis B and C was observed in $17.65 \%(n=39)$ cases. According to Child Pugh score, 9.5\% cases were in class A, $32.58 \%$ were in class B and $57.92 \%$ were in class C. Frequency of malnutrition in chronic liver disease patients was $62.44 \%(138 / 221)$. Comparison of the frequency of malnutrition in different stages of CLD patients and comparison with other variables is shown in table 2. Rate of malnutrition was significantly high in class B and C ( $p=0.002)$. Effect modifiers like age, gender hepatitis and duration of cirrhosis were control through the stratification analysis. Table 2 showed that rate of malnutrition in chronic liver disease was significantly high in 51 to 60 years of age $(p=0.042)$ while rate of malnutrition in chronic liver disease was not significant between male and female. Rate of malnutrition was also observed to be significantly high in those cases who were positive for both hepatitis like $B$ and $C(p=0.001)$. Effect of duration of cirrhosis was also not statistically significant with malnutrition. 
Rate of malnutrition in different stages of CLD patients was also high in class $B$ and class $C$ for below and equal to 40 years of age, while it was not significant for the age group 41 to 50 and above 50 years of age patients. Rate of malnutrition in different stages of CLD patients was also high in class B and class C in male and female. Similarly rate of malnutrition in different stages of CLD patients was also observed with respect to hepatitis status and duration of cirrhosis respectively.

Table 2: Comparison of the frequency of malnutrition in different stages of CLD patients

\begin{tabular}{|c|c|c|c|c|c|c|}
\hline \multirow{2}{*}{\multicolumn{2}{|c|}{ Variables }} & \multicolumn{2}{|c|}{ Malnutrition } & \multirow{2}{*}{ Total } & \multirow{2}{*}{ Chi-Square } & \multirow{2}{*}{ P-Value } \\
\hline & & Yes $(n=138)$ & No $(n=83)$ & & & \\
\hline \multirow{3}{*}{$\begin{array}{l}\text { Different Stages According to } \\
\text { Child Pugh Score }\end{array}$} & Class A & $6(28.6 \%)$ & $15(71.4 \%)$ & 21 & \multirow{3}{*}{12.47} & \multirow{3}{*}{0.002} \\
\hline & Class B & $51(70.8 \%)$ & $21(29.2 \%)$ & 72 & & \\
\hline & Class C & $81(63.3 \%)$ & $47(36.7 \%)$ & 128 & & \\
\hline \multirow{3}{*}{ Age groups } & $\leq 40$ Years & $34(63 \%)$ & $20(37 \%)$ & 54 & \multirow{3}{*}{6.34} & \multirow{3}{*}{0.042} \\
\hline & 41 to 50 Years & $31(50 \%)$ & $31(50 \%)$ & 62 & & \\
\hline & 51 to 60 Years & $73(69.5 \%)$ & $32(30.5 \%)$ & 105 & & \\
\hline \multirow{2}{*}{ Gender } & Male & $88(64.7 \%)$ & $48(35.3 \%)$ & 136 & \multirow{2}{*}{0.77} & \multirow{2}{*}{0.38} \\
\hline & Female & $50(58.8 \%)$ & $35(41.2 \%)$ & 85 & & \\
\hline \multirow{3}{*}{ Hepatitis Status } & Hepatitis-B & $22(50 \%)$ & $22(50 \%)$ & 44 & \multirow{3}{*}{13.61} & \multirow{3}{*}{0.001} \\
\hline & Hepatitis-C & $82(59.4 \%)$ & $56(40.6 \%)$ & 138 & & \\
\hline & Both (Hepatitis A and B) & $34(87.2 \%)$ & $5(12.8 \%)$ & 39 & & \\
\hline \multirow{3}{*}{ Duration of Cirrhosis } & $\leq 5$ months & $99(67.8 \%)$ & $47(32.2 \%)$ & 146 & \multirow{3}{*}{5.34} & \multirow{3}{*}{0.069} \\
\hline & 5.1 to 10 months & $26(53.1 \%)$ & $23(46.9 \%)$ & 49 & & \\
\hline & $>10$ months & $13(50 \%)$ & $13(50 \%)$ & 26 & & \\
\hline \multirow{3}{*}{$\begin{array}{l}\text { Child Pugh Score for patients of } \\
<40 \text { years age }\end{array}$} & Class A & $3(25 \%)$ & $9(75 \%)$ & & & \\
\hline & Class B & $10(83.3 \%)$ & $2(16.7 \%)$ & & 10.18 & 0.006 \\
\hline & Class $\mathrm{C}$ & $21(70 \%)$ & $9(30 \%)$ & & & \\
\hline & Class A & $1(33.3 \%)$ & $2(66.7 \%)$ & 3 & & \\
\hline Child Pugh Score for patients of & Class B & $11(52.4 \%)$ & $10(47.6 \%)$ & 21 & 0.38 & 0.82 \\
\hline & Class C & $19(50 \%)$ & $19(50 \%)$ & 38 & & \\
\hline & Class A & $2(33.3 \%)$ & $4(66.7 \%)$ & 6 & & \\
\hline Child Pugh score for patients & Class B & $30(76.9 \%)$ & $9(23.1 \%)$ & 39 & 4.75 & 0.093 \\
\hline & Class C & $41(68.3 \%)$ & $19(31.7 \%)$ & 60 & & \\
\hline & Class A & $3(30 \%)$ & $7(70 \%)$ & 10 & & \\
\hline Child Pugh Score for males & Class B & $33(70.2 \%)$ & $14(29.8 \%)$ & 47 & 5.94 & 0.05 \\
\hline & Class C & $52(65.8 \%)$ & $27(34.2 \%)$ & 79 & & \\
\hline & Class A & $3(27.3 \%)$ & $8(72.7 \%)$ & 11 & & \\
\hline Child Pugh Score for females & Class B & $18(72 \%)$ & $7(28 \%)$ & 25 & 6.31 & 0.043 \\
\hline & Class $\mathrm{C}$ & $29(59.2 \%)$ & $20(40.8 \%)$ & 49 & & \\
\hline & Class A & $2(25 \%)$ & $6(75 \%)$ & 8 & & \\
\hline Frequency of Child Pugn scores & Class B & $4(50 \%)$ & $4(50 \%)$ & 8 & 2.57 & 0.27 \\
\hline & Class C & $16(57.1 \%)$ & $12(42.9 \%)$ & 28 & & \\
\hline & Class A & $0(0 \%)$ & $7(100 \%)$ & 7 & & \\
\hline Frequency of Child Pugh Scores & Class B & $26(65 \%)$ & $14(35 \%)$ & 40 & 10.93 & 0.004 \\
\hline & Class C & $56(61.5 \%)$ & $35(38.5 \%)$ & 91 & & \\
\hline Frequency of Child Pugh Scores & Class A & $4(66.7 \%)$ & $2(33.3 \%)$ & 6 & & \\
\hline for patients with both Hepatitis & Class B & $21(87.5 \%)$ & $3(12.5 \%)$ & 24 & 3.58 & 0.167 \\
\hline B \& Hepatitis C & Class $\mathrm{C}$ & $9(100 \%)$ & $0(0 \%)$ & 9 & & \\
\hline & Class A & $3(28.6 \%)$ & $5(71.4 \%)$ & 7 & & \\
\hline Duration of symptoms less than & Class B & $37(72.5 \%)$ & $14(27.5 \%)$ & 51 & 5.46 & 0.065 \\
\hline & Class C & $60(68.2 \%)$ & $28(31.8 \%)$ & 88 & & \\
\hline & Class A & $2(33.3 \%)$ & $4(66.7 \%)$ & 6 & & \\
\hline Duration of symptoms of 5.1 to & Class B & $7(63.6 \%)$ & $4(36.4 \%)$ & 11 & 1.43 & 0.48 \\
\hline & Class $\mathrm{C}$ & $17(63.1 \%)$ & $15(46.9 \%)$ & 32 & & \\
\hline & Class A & $2(25 \%)$ & $6(75 \%)$ & 8 & & \\
\hline Duration of symptoms greater & Class B & $7(70 \%)$ & $3(30 \%)$ & 10 & 3.6 & 0.165 \\
\hline & Class C & $4(50 \%)$ & $4(50 \%)$ & 8 & & \\
\hline
\end{tabular}


Lack of healthy nutrition and diet is a typical complication experienced while treating patients with chronic liver disease and can impact the patient's survival over some stretch of time. The prevalence of protein energy malnutrition has been observed in $10 \%$ to $100 \%$ of the patients with liver diseases being particularly high in liver cirrhosis. ${ }^{7}$ Little work has been done to explore the incidence of malnutrition among non-alcoholic liver disease cases. ${ }^{8}$ Malnutrition may be found in $20 \%$ of patients who have a well-compensated chronic liver disease. Similarly, in patients having severely malfunctioning liver the prevalence is $60 .{ }^{9}$

Malnutrition in liver transplanted patients is one of the predictive factors for the increased morbidity and mortality as seen in these highly complex cases. The number of complications increases with malnutrition and the impact of a full-fledged nutritional intervention on patient outcomes may vary with the etiology and severity of the illness. Nutritional status in cirrhotic patients should be assessed regularly in order to implement an adequate nutritional intervention designed as per the needs of the patient.

Use of zinc supplementation as an adjunct therapy for hepatic encephalopathy and regularly give zinc supplements to patients with cirrhosis because they are almost always zinc deficient. We should attempt to provide patients with information on dosing, potential side effects, and issues concerning product safety. Early identification and treatment of malnutrition will lead to much better disease outcomes for these patients. Further this improvement would result in prevention of complications of the disease and improved outcomes after undergoing a liver transplant procedure. In a study of 396 patients diagnosed with cirrhosis, a declining nutritional status was seen in $49 \%$ of the study population with ascites. Thus, indicating that patients who are hospitalized have a high prevalence of malnutrition as they are in a much worse clinical state as compared to patients who are not admitted. Reduced caloric intake was determined to be an independent risk factor for mortality. However, this was more true when cases were followed for a short duration of time. No clinical benefit was observed when oral supplementation was given after failure of enteral feeding. It is recommended that enteral feeding be started early at the first signs of deterioration. ${ }^{9}$ In this study average age of the patient population was $48.12 \pm 8.521$ years. In a study by Butt $e t a l^{5}$ the mean age of patients was observed to be 53 years and the mean age at time of diagnosis for chronic hepatitis and liver cirrhosis were 40 years and 57 years, respectively. Reflecting the progression of Hepatitis B and C towards liver cirrhosis over $10-15$ years. There were $61.54 \%$ male and $38.46 \%$ female in present study. In Butt et al study $62 \%$ of patients were male and the rest of $38 \%$ of the cases were female.
$50 \%$ of our patient population had a low socioeconomic status, which reflects the state of health in the general population. In addition, this group is likely exposed to a wide variety of risk factors and may not have had certain privileges that patients in developing countries might have. Regarding hepatitis status, hepatitis-B was observed in $19.91 \%$ cases, hepatitis-C was $65.44 \%$ and both hepatitis B and C was observed in $17.65 \%$ cases. According to child pugh score, $9.5 \%$ cases were in class A, $32.58 \%$ were in class B and $57.92 \%$ were in class C. Malnourished patients with chronic liver disease are well known in medicine to have a higher rate of complications and overall, an increased rate of mortality. ${ }^{10,11,12}$ This is in addition to the costs incurred by the hospital and the health system as a whole. It determines both the patient's quality of life and their survival.12,13 Frequency of malnutrition in chronic liver disease patients was $62.44 \%$ $(138 / 221)$ in our study. According to Shaheen et al, $82.6 \%$ of cirrhotic patients suffer malnutrition. ${ }^{5}$ Malnutrition in patients with liver disease has been reported to varying degree from $10 \%$ to $100 \%$ in different studies conducted at different institutes. ${ }^{14,15}$ It is a very good prognostic factor ${ }^{16,17}$ and an independent predictor of mortality. ${ }^{18}$ In present study rate of malnutrition was significantly high in class B and C $(\mathrm{p}=0.002)$. According to Ndhara et al, ${ }^{6}$ among 38 patients, there were 4 patients in Child Pugh A of which $1(25 \%)$ is malnourished, 15 in Child Pugh B of which $07(46.66 \%)$ were malnourished and 19 patients in Child Pugh C of which 17(89.47\%) were malnourished.

\section{CONCLUSION}

This cross-sectional study reported a common occurrence of malnutrition in patients with chronic liver disease of viral causes and the degree of malnutrition was found to be positively associated with the condition of the patient and liver pathology.

\section{LIMITATIONS}

This study is a single center study with a small sample size.

\section{SUGGESTIONS / RECOMMENDATIONS}

Further large-scale studies conducted at different institutions. Malnutrition should be recognized as a hindrance to effective treatment of CLD.

\section{CONFLICT OF INTEREST / DISCLOSURE} None.

\section{ACKNOWLEDGEMENTS}

All Faculty and Staff of Dr. Ruth K.M. Pfau Civil Hospital Karachi.

\section{REFERENCES}

1. Moctezuma-Velazquez C, Garcia-Juarez I, Soto-Solis R, Hernandez-Cortes J, Torre A. Nutritional assessment and 
treatment of patients with liver cirrhosis. Nutrition. 2013;29(12):1279-85.

2. Arshad A, Ashfaq UA. Epidemiology of Hepatitis C Infection in Pakistan: Current Estimate and Major Risk Factors. Crit Rev Eukaryot Gene Expr. 2017;27(1):63-77.

3. Eghtesad S, Poustchi H, Malekzadeh R. Malnutrition in liver cirrhosis: the influence of protein and sodium. Middle East J Dig Dis. 2013;5(2):65-75.

4. Butt S, Ahmed P, Liaqat P, Ahmad H. A study of malnutrition among chronic liver disease patients. Pak J Nutr. 2009;8(9):1465-71.

5. Ndraha S, Simadibrata M. Child pugh and male gender were related to nutritional status of liver cirrhosis patients in Koja hospital Jakarta. Indonesia J Gastroenterology Hepatology and digestive endoscopy. 2009;10(3):110-12.

6. Oey RC, Aarts P, Erler NS, Metselaar HJ, Lakenman PLM, Riemslag Baas-van der Ree S, et al. Identification and prognostic impact of malnutrition in a population screened for liver transplantation. Clin Nutr ESPEN. 2020;36:36-44.

7. Buchard B, Boirie Y, Cassagnes L, Lamblin G, Coilly A, Abergel A. Assessment of Malnutrition, Sarcopenia and Frailty in Patients with Cirrhosis: Which Tools Should We Use in Clinical Practice. Nutrients. 2020;12(1):186.

8. Huynh DK, Selvanderan SP, Harley HA, Holloway RH, Nguyen NQ. Nutritional care in hospitalized patients with chronic liver disease. World J Gastroenterol. 2015;21(45):12835-42.
9. Thuluvath PJ and Triger DR. Evaluation of nutritional status by using anthropometry in adults with alcoholic and nonalcoholic liver disease. Am J Clin Nutr. 1994;60(2):269-73.

10. Pérez-Latorre L, Sánchez-Conde M, Miralles P, López JC, Parras F, Tejerina F, et al. Prognostic value of liver stiffness in $\mathrm{HIV} / \mathrm{HCV}$ Coinfected patients with decompensated cirrhosis. BMC Infect Dis. 2018;18(1):170.

11. Vidot H, Kline K, Cheng R, Finegan L, Lin A, Kempler E, et al. The Relationship of Obesity, Nutritional Status and Muscle Wasting in Patients Assessed for Liver Transplantation. Nutrients. 2019;11(9):2097.

12. Tajika M, Kato $M$ and Mohri H. Prognostic value of energy metabolism in patients with liver cirrhosis. Nutr. 2002;18(3):229-34.

13. Matos C, Porayko M and Francisco-Ziller N. Nutrition and chronic liver disease. J Clin Gastroenterol. 2002;35(5):391-7.

14. Ghufran A. Nutrition in Chronic Liver Disease: A Point-of-Care Review. Nutr Clin Pract. 2020;35(2):211-7.

15. Gundling F, Teich N and Strebel HM. Nutrition in liver cirrhosis. Med Klin. 2007;102(3):435-44.

16. Tsiaousi ET, Hatzitolios IA and Trygonis SK. Malnutrition in end stage liver disease: Recommendations and nutritional support. J Gastroenterol and Hepatol. 2008;23(4):527-33.

17. Henkel A. and Buchman AL. Nutritional Support in Chronic Liver Disease. Nat Clin Pract Gastroenrol Hepatol. 2006;3:202-9. 